\title{
EVIDENCE FOR AN AGE-DEPENDENT PYROGENIC THRESHOLD OF PLASMODIUM FALCIPARUM PARASITEMIA IN HIGHLY ENDEMIC POPULATIONS
}

\author{
CHRISTOPHE ROGIER, DANIEL COMMENGES, AND JEAN-FRANCOIS/TRAPE \\ Institut Pasteur de Dakar, Dakar, Senegal; Institut National de la Sante et de la Recherche \\ Medicale (INSERM), Unite 330, Universite de Bordeaux II, Bordeaux, France; Institut Francais \\ de Recherche Scientifique pour le Developpement en Cooperation (ORSTOM), Dakar, Senegal
}

\begin{abstract}
The high prevalence of asymptomatic malaria infections and the nonspecific signs and symptoms of the disease make the individual diagnosis of clinical malaria uncertain in highly endemic areas. Longitudinal data obtained during a four-month period from a daily survey of 200 permanent inhabitants (one month-83 years old) living in a holoendemic area were analyzed in a random-effects logistic regression model to investigate the relationship between the level of Plasmodium falciparum parasitemia and risk of fever. It was not possible to build a model that described/ summarized correctly this relationship by a continuous function. Findings provide evidence for an age-dependent threshold effect of parasitemia on the occurrence of fever. The level of this threshold varied by 2.45 trophozoites per leukocyte, maximum at one year of age, to 0.5 trophozoites per leukocyte, minimum at 60 years of age. When the parasite density of a person 'crossed the threshold level corresponding to his or her age, the individual's risk of fever was multiplied by $44\left(95 \%{ }^{\prime}\right.$ confidence interval $\left.=13.6-144.8\right)$. The existence of this threshold effect allows parasite density to be used to distinguish malaria attacks from other causes of fever within an individual and should facilitate the accurate evaluation of the incidence of clinical malaria in highly endemic areas.
\end{abstract}

Because of the high prevalence of asymptomatic malaria infections and the nonspecific signs and symptoms of the disease, the diagnosis of clinical malaria presents difficult methodologic problems in highly endemic areas. ${ }^{1-3}$ In the past, these difficulties have proven a major obstacle in the evaluation of malaria control strategies, and at the present time the same difficulties are being encountered in attempts to estimate the efficacy of recently developed malaria vaccines. To estimate the fraction of fever cases that are attributable to malaria, methods based on the measurement of parasite density have been developed in recent years. ${ }^{4-9}$ However, the intrinsic nature of the relationship between parasitemia and fever at the individual level has never been investigated, nor have the variations in tolerance of parasitemia among individuals, and there is no consensus of opinion as to what criteria define a clinical episode of malaria. ${ }^{10-}$ 12 Using logistic regression methods, we analyzed longitudinal data from inhabitants of a village in Senegal where Plasmodium falciparum malaria is holoendemic. ${ }^{13}$ Our findings provide evidence for an age-dependent threshold effect in the relationship between the level of parasitemia and the occurrence of fever. As a result of this threshold effect, the parasite density measurement makes it possible to distinguish malaria attacks from other causes of fever at the individual level.

\section{POPULATION AND METHODS}

Study area. The study area, the protocols of medical and epidemiologic surveillance, and the main characteristics of malaria in the study population have been presented elsewhere. ${ }^{13}$ Briefly, to identify all episodes of fever, the 247 inhabitants of Dielmo village were put under daily medical surveillance from June 1 to September 30, 1990. Thick blood films were made and medical examinations were conducted for each illness episode. In addition, three times a week (Monday, Wednesday, and Friday or Tuesday, Thursday, and Saturday) each villager was visited at home; tem- perature was recorded and a questionnaire was filled out listing symptoms that had occurred during the previous $48 \mathrm{hr}$. Twice a week (Monday and Friday or Tuesday and Saturday) a thick blood film was paired with the temperature record. In all, 8,636 simultaneous observations of parasitemia and temperature were made from 247 individuals (males $=125$, females $=122$ ) from one month to 83 years of age.

Definition of case and control observations. In the present analysis, we eliminated data from 25 persons (842 observations) who were irregularly monitored: three persons died (prematurity, bronchopneumonia and hepatocarcinoma, respectively), 10 persons were absent for a period of 11-30 days, and 12 persons were absent for more than a month. We also eliminated data from 16 persons (605 observations) who had stayed for a long period in low endemic areas, and six pregnant women (292 observations). We also excluded all observations following antimalarial treatment $(1,302 \mathrm{ob}-$ servations).

Case observations. Individual observations were considered to be fever cases if the axillary temperature was $38^{\circ} \mathrm{C}$ or higher, or the rectal temperature was $38.5^{\circ} \mathrm{C}$ or higher. In a second analysis, individual observations were considered to be fever cases if the axillary temperature was $37.7^{\circ} \mathrm{C}$ or higher, or the rectal temperature was $38.2^{\circ} \mathrm{C}$ or higher. Two febrile episodes were analyzed separately if they were separated by more than $72 \mathrm{hr}$ without fever or associated symptoms (hot sweats associated with one or more of the following: shivering, asthenia, anorexia, nausea, vomiting, or headache). Only one measurement of parasitemia was taken into account for each febrile episode. When several measurements of parasitemia were available for the same febrile episode, we took into account the highest figure in a first analysis and the lowest figure in a second analysis. Consequently, we excluded 914 observations of parasitemia made during febrile episodes taken into account by another measurement of parasite density (made during these same febrile episodes).

Control observations. Owing to the erratic nature of hy- 


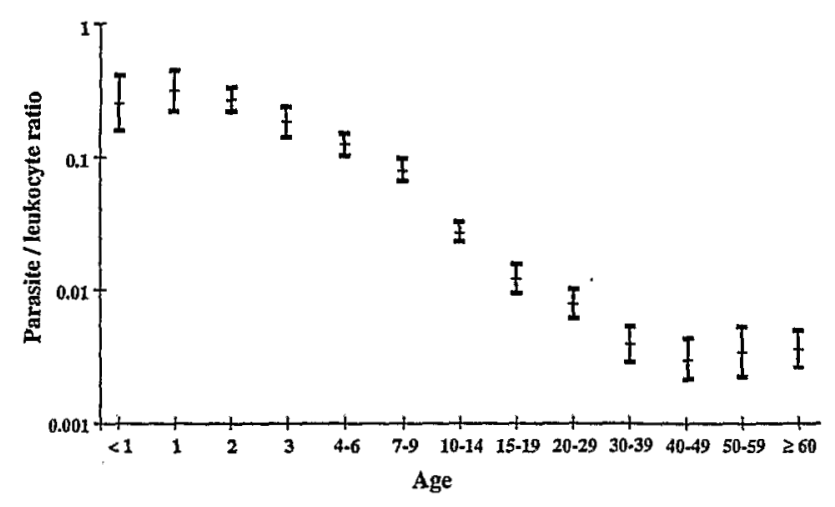

FlGURE 1. Age (years) distribution of the mean Plasmodium falciparum parasitemia (geometric mean of the ratio number of trophozoites/number of leukocytes and $95 \%$ confidence intervals) in 4,936 thick blood film examinations in 200 individuals who were asymptomatic at least $72 \mathrm{hr}$ before and after sampling. Two hundred oil-immersion fields (about $0.5 \mu \mathrm{l}$ of blood) were examined on each slide. Mean leukocyte counts in the study population range from $12,800 / \mu \mathrm{l}$ in infants to $5,400 / \mu \mathrm{l}$ in adults more than 60 years of age.

perthermia, individual observations were considered to be asymptomatic controls if the axillary temperature was $37.9^{\circ} \mathrm{C} / 37.6^{\circ} \mathrm{C}$ (rectal temperature $=38.4^{\circ} \mathrm{C} / 38.1^{\circ} \mathrm{C}$ ) or lower, and if no symptoms associated with fever were recorded during the $72 \mathrm{hr}$ preceding or following the collection of thick blood films. We excluded 596 observations with axillary temperature lower than $38^{\circ} \mathrm{C} / 37.7^{\circ} \mathrm{C}$ (rectal temperature $=38.4^{\circ} \mathrm{C} / 38.1^{\circ} \mathrm{C}$ ) and fever-associated symptoms recorded during the $72 \mathrm{hr}$ preceding or following the collection of thick blood films.

In all, 3,560 observations were excluded because of one or more of the above reasons and 5,076 simultaneous measurements of parasitemia and temperature in 200 individuals (males $=107$, females $=93$ ) from one month to 83 years of age were analyzed.

Models. We analyzed the risk of fever as a logistic function of age and parasitemia. To take into account the interdependence of successive observations in the same individuals, we used a random-effects logistic regression model, ${ }^{14}$ which is available in the software package EGRET ${ }^{\oplus}$ (Statistics and Epidemiology Research Corp., Seattle, WA). ${ }^{15}$ With this model, the estimated odds ratios can be considered as estimations of the individual relative risk of fever associated with a variation in parasitemia. ${ }^{16}$ The correlation between observations is assumed to be induced by the existence of a person-cluster effect that is added to each logit in the personcluster. When the model includes explanatory variables the correlation structure cannot be easily characterized and the correlations are generally not equal.

The logit of the probability $\pi i j$ that the individual $i$ presents a febrile episode during the observation $j$ can be expressed in the form of a linear function of age $z_{\mathrm{i}}$ and parasite density $x_{\mathrm{ij}}$. Compared with other methods of taking age into account, ${ }^{17}$ the best fit was obtained using a series of $\mathrm{k}=3$ dummy variables $z_{\mathrm{ik}}$ coding for the following age groups: 0 $1,2-6,7-12$, and $\geq 13$ years. Several different functions $f\left(x_{i j}\right)$ of parasitemia were fitted into the following model in which $\beta_{0}$ is a constant, $\alpha i$ is the random-effects individual term, and $\beta_{1}$ and $\beta_{2}$ are the regression coefficients:

$$
\left.\operatorname{logit}\left(\pi_{i j}\right)=\beta_{0}+\sum_{k=1}^{3} \beta_{1 k} z_{i k}+\beta_{2} f\left(x_{i j}\right)+\alpha_{i} \cdot \quad \text { (model } A\right)
$$

The object of the analysis was to test the existence of a pyrogenic threshold effect of parasitemia, meaning a discontinuous relationship between parasite density and risk of fever. Thus, we decided to use a two-step modeling strategy. At first, we researched the best model describing the parasitemia-fever relationship as a continuous function. Then we tested for the existence of a discontinuous relationship by introducing a threshold variable into the previous continuous function model. The different models were compared according to the maximum likelihood (minimum deviance) using the Akaike method ${ }^{17}$ and we tested the goodness of fit using the Tsiatis method. ${ }^{18}$ At each modeling step we tested for an individual-random effect and for a linear interaction of parasite density and age or month of survey.

\section{RESULTS}

Figure 1 shows that average asymptomatic parasitemia was highest in children from 12 to 23 months of age. From then on, it decreased with age $(P<0.001)$, first rapidly in children, then slowly in adults, as is classically observed in areas of malaria holoendemicity. ${ }^{19}$ Table 1 shows that the risk of fever considerably increased with parasitemia $(P<$ 0.001 ). The risk of fever decreased with age (Table 2). There was no difference of fever risk or modifier effect due to gender.

At first, the relationship between parasite density and fever was assumed to follow a smooth and continuous increasing function. This approach avoids the need for an arbitrary

TABLE 1

Distribution of 5,076 cases (axillary temperature $\geq 38^{\circ} \mathrm{C}$ or rectal temperature $\geq 38.5^{\circ} \mathrm{C}$ ) and control observations in relation to density of Plasmodium falciparum parasitemia and age in 200 permanent residents of Dielmo, Senegal, June-September 1990*

\begin{tabular}{|c|c|c|c|c|c|c|c|c|c|c|c|c|}
\hline \multirow[b]{2}{*}{ Parasitemiat } & \multicolumn{2}{|c|}{ Total } & \multirow[b]{2}{*}{ OR } & \multirow[b]{2}{*}{$95 \% \mathrm{CI}$} & \multicolumn{2}{|c|}{$0-1$ years } & \multicolumn{2}{|c|}{ 2-6 years } & \multicolumn{2}{|c|}{$7-12$ years } & \multicolumn{2}{|c|}{$\geqslant 13$ years } \\
\hline & Case & Control & & & Case & Control & Case & Control & Case & Control & Case & Control \\
\hline 0 & 11 & 1,899 & 1 & - & 3 & 57 & 0 & 59 & 0 & 82 & 8 & 1,701 \\
\hline$<0.01$ & 6 & 898 & 1.1 & $0.4-3.1$ & 0 & 6 & 0 & 29 & 5 & 102 & 1 & 761 \\
\hline $0.01-<0.1$ & 15 & 1,051 & 2.5 & $1.1-5.7$ & 1 & 27 & 6 & 158 & 6 & 335 & 2 & 531 \\
\hline $0.1-<1$ & 40 & 974 & 7.1 & $3.4-14.7$ & 11 & 77 & 20 & 360 & 6 & 331 & 3 & 206 \\
\hline $1-<2$ & 12 & 92 & 22.0 & $9.0-56.5$ & 3 & 31 & 6 & 41 & 1 & 18 & 2 & 2 \\
\hline$\geq 2$ & 56 & 22 & 439.5 & $192-1,032$ & 16 & 7 & 31 & 10 & 7 & 3 & 2 & 2 \\
\hline Total & 140 & 4,936 & & & 34 & 205 & 63 & 657 & 25 & 871 & 18 & 3,203 \\
\hline
\end{tabular}

* The observations following antimalaria treatment are excluded. $O R=$ odds ratio; $95 \% \mathrm{CI}=95 \%$ confidence interval.

$\dagger$ Parasite/leukocyle ratio. 
TABLE 2

Age distribution of 204 fever episodes in 200 permanent residents, including observations following antimalarial treatment, of Dielmo, Senegal, June-September 1990

\begin{tabular}{cccc}
\hline Age group & $\begin{array}{c}\text { No. of } \\
\text { persons }\end{array}$ & $\begin{array}{c}\text { No. of fever } \\
\text { episodes }\end{array}$ & $\begin{array}{c}\text { Mean no. of fever } \\
\text { episodes per person }\end{array}$ \\
\hline 1-23 months & 18 & 53 & 2.94 \\
2-6 years & 43 & 107 & 2.49 \\
7-12 years & 33 & 26 & 0.79 \\
$13-19$ years & 26 & 4 & 0.15 \\
$20-39$ years & 41 & 7 & 0.17 \\
$40-59$ years & 23 & 4 & 0.17 \\
$\geq 60$ years & 16 & 3 & 0.19 \\
\hline
\end{tabular}

grouping of categories of parasite density. ${ }^{9}$ The different tested functions $f\left(x_{i j}\right)$ of parasitemia were linear in $x$, quadratic in $x$, and linear in $\log (x)$ and th power of $x$. Looking for the best manner to describe the fever risk as a continuous function of parasite density, the maximum likelihood solution was obtained for the rth power function of parasitemia. Figure 2 shows the variations in deviance as a function of the exponent $r$. The deviance was minimized when $r=0.82$ (Table 3, model 1). However, there was a significant interaction between the effects of parasitemia and age (Table 3, model 2, likelihood ratio statistic, $P<0.001$ ). For the same parasite density, the risk of fever increased with age. The individual random effect was not significant. The goodness of fit test indicated that the best tested continuous function model did not fit well $(P<0.001)$.

The concept of a pyrogenic threshold is a very old concept in malariology. ${ }^{20,21}$ We then looked for the existence of a threshold effect in addition to the previous continuous effect of parasitemia. Thus, we had to 1) define the shape and the level of the thresholds to be tested and 2) test the fit of the corresponding discontinuous function models. To test these threshold models, we introduced a binary variable $s i j$ in the previous continuous effect model:

$$
\begin{aligned}
\operatorname{logit}\left(\pi_{i j}\right)= & \beta_{0}+\sum_{k=1}^{3} \beta_{1 k} z_{i k}+\beta_{2}\left(x_{i j}\right)^{0.82} \\
& +\beta_{3} s_{i j}+\alpha_{i} .
\end{aligned}
$$

The variable $s i j$ takes the value 0 when the $j$ th parasitemia of the individual $i$ is below the tested threshold level and the value 1 when it is higher.

We first considered the possibility of a constant age-independent threshold. This is the simplest threshold shape. A series of models were fitted with different fixed values (from 0.1 to 3 parasites per leukocyte) of this threshold level to determine the maximum likelihood solution. The best value for the constant age-independent threshold was 1.9 parasites per leukocyte. Compared with the previous continuous function models, deviance was only slightly improved (Table 3, models 3 and 4).

The existence of a pyrogenic threshold whose level decreases with age in individuals continuously exposed to malaria was suggested by previous observations in the Congo. 4,6 The patterns of distribution with age of symptomatic and asymptomatic parasitemia in Dielmo inhabitants and the existence of an interaction between the effects of age and parasitemia suggested that this was a relevant approach. The

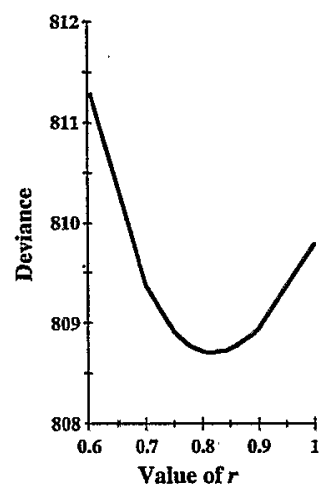

FIGURE 2. Fit of regression model by $r$. The parameter $r$ is the exponent of the power function of parasite density used for modeling the relationship between parasitemia and fever risk as a continuous function. The deviance is minimized when $r=0.82$. The deviance is equal to $-2 \ln$ (likelihood of the current model). Age effects are adjusted using a series of three dummy variables coding for age groups.

threshold level would be maximum in children from 12 to 23 months of age, then would decrease with age, rapidly in children, then slowly in adults, thus suggesting a decreasing exponential function of age. Since it was necessary to define precisely the shape and the level of the age-dependent threshold to be tested, we decided to define it as a function of age and five parameters $(a, b, c, d$, and $e$ ) whose values could be estimated by successive fits. We defined the threshold level as the value $d$ below the age of 12 months, value $e$ between 12 and 23 months, and after 23 months by the following exponential function of age: $h\left(z_{\mathrm{i}}\right)=\left[\exp \left[\left(1-z_{\mathrm{i}} l\right.\right.\right.$ a) $\left.\left.\log _{e}(100(b-c))\right]+(100 c)\right] / 100$.

The inverse exponential function is the simplest and most widely used type of decaying function that approaches a limit when the independent variable is large. Using the $\mathrm{B}$ model, we estimated the values of parameters $a, b, c, d$, and $e$ by successive fitting of data, by varying them independently from each other, and by taking into consideration the max-

TABLE 3

Estimates of deviance and AIC for different regression models on

\begin{tabular}{|c|c|c|c|c|}
\hline $\begin{array}{l}\text { Model } \\
\text { no. }\end{array}$ & Parameters & $\begin{array}{l}\text { Degrees of } \\
\text { freedom }\end{array}$ & Deviance & AIC \\
\hline 1 & $\begin{array}{l}\text { Age } \\
\text { Parasitemia }\end{array}$ & 5,070 & 808.7 & 816.7 \\
\hline 2 & $\begin{array}{l}\text { Age } \\
\text { Parasitemia } \\
\text { Age } \times \text { parasitemia }\end{array}$ & 5,067 & 791.2 & 805.2 \\
\hline 3 & $\begin{array}{l}\text { Age } \\
\text { Parasitemia } \\
\text { Constant threshold }\end{array}$ & 5,069 & 804.6 & 814.6 \\
\hline 4 & $\begin{array}{l}\text { Age } \\
\text { Parasitemia } \\
\text { Age } \times \text { parasitemia } \\
\text { Constant threshold }\end{array}$ & 5,066 & 788.1 & 804.1 \\
\hline 5 & $\begin{array}{l}\text { Age } \\
\text { Parasitemia } \\
\text { Age-dependent threshold }\end{array}$ & 5,064 & 767.2 & 787.2 \\
\hline
\end{tabular}
parasite density* 

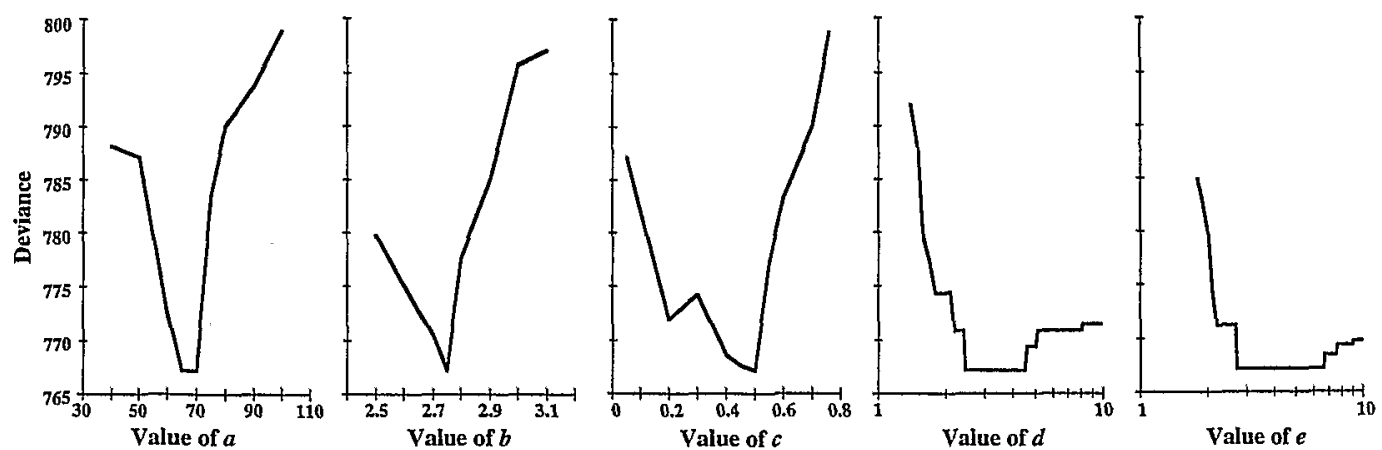

FIGURE 3. Fit of regression model by $a, b, e, d$, and $e$. Because the model is nonlinear in these parameters, they cannot be estimated directly by standard logistic regression software. A series of models were fitted with fixed values. The maximum likelihood estimates of $a, b$, and $c$ were first obtained, and $d$ and $e$ were fixed at the values of the function $h\left(z_{i}\right)$ for the ages 0 and 1 . The tested values of $a, b$, and $c$ varied respectively from 15 to $100,1.5$ to 4 , and 0 to 1 . Thereafter, the tested values of $d$ and $e$ varied from 0.5 to 10 . The deviance varies as a function of these parameters, each fixed at their maximum likelihood estimated values. The deviance is equal to -2 In(likelihood of the current model).

imum likelihood solution. Figure 3 shows that the lowest deviances were obtained for $a=70, b=2.75, c=0.50, d$ $=2.45$, and $e=2.70$. The level of the corresponding threshold could be calculated from the age of each person and the estimated values of these parameters. For example, the level of the threshold for a seven-year-old child was [exp[(1 - 7] $\left.\left.70) \log _{e}(100(2.75-0.5))\right]+(100 \times 0.5)\right] / 100=1.8$ parasites/leukocyte.

Thus, the level of the age-dependent threshold was 2.45 parasites/leukocyte (value of $d$ ) up to the age of 12 months, 2.70 parasites/leukocyte (value of $e$ ) between 12 and 23 months of age, 2.40 parasites/leukocyte at two years of age, 2.00 parasites/leukocyte at five years of age, 1.55 parasites/ leukocyte at 10 years of age, and 0.50 parasites/leukocyte (value of $c$ ) in adults more than 60 years of age (Figure 4).

We then tested for the significance of the age-dependent threshold effect added to the continuous effect model. The age-dependent threshold effect was significant (Table 3, model $5 ; P<10^{-6}$ ). There was no significant interaction between the effects of age and parasitemia, between the effects of month of survey and parasitemia, or between the effects of parasite density and the crossing of the threshold. The individual-random effect was not significant and the Tsiatis's test ${ }^{18}$ indicated that the threshold effect model fitted well. Figure 5 shows the observed and fitted proportions of cases for this model. When a person's parasitemia crossed the threshold level corresponding to his or her age, the sub-

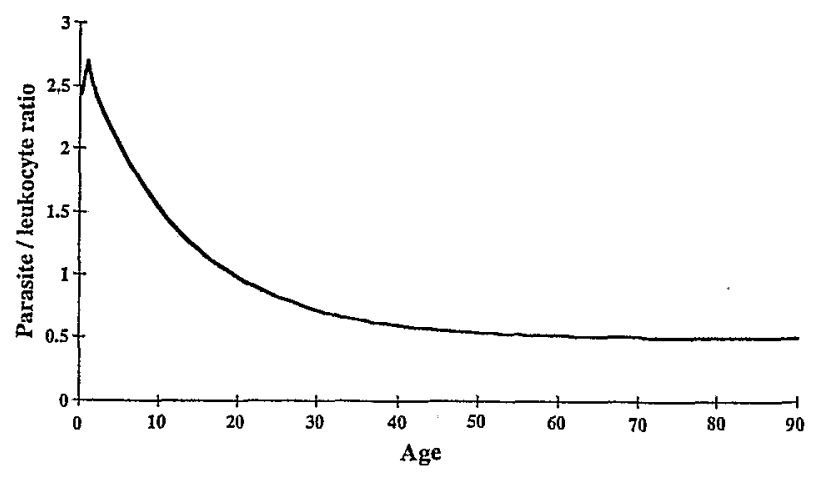

FIGURE 4. Level of pyrogenic threshold by age (years). ject-specific fever risk was multiplied by an odds ratio (OR) $=44.4(95 \%$ confidence interval $[\mathrm{CI}]=13.6-144.8)$. Irrespective of the crossing of the threshold, an increase of 0.5 in the parasite/leukocyte ratio was associated with a multiplication of fever risk by an $\mathrm{OR}=1.35(95 \% \mathrm{CI}=1.34-$ 1.36). The increase in fever risk as a function of parasitemia and age is shown graphically in Figure 6.

Taking into account the minimal parasitemia registered during episodes of fever, we obtained similar results. We obtained the same estimation of parameters $a, b, c, d$, and $e$ of the threshold level. The increase in fever risk by crossing the threshold was an $\mathrm{OR}=45.6(95 \% \mathrm{CI}=13.7-151.7)$ and the increase in risk with parasitemia irrespective of fever threshold was an $\mathrm{OR}=1.26(95 \% \mathrm{CI}=1.25-1.27)$.

If fever was defined as an axillary temperature of $37.7^{\circ} \mathrm{C}$ or higher, we also came to similar conclusions. The increase in fever risk by crossing the threshold was an $\mathrm{OR}=28.0$ $(95 \% \mathrm{CI}=8.9-87.6)$ and the increase in risk with parasitemia irrespective of fever threshold was an OR $=1.42(95 \%$ $\mathrm{CI}=1.41-1.44)$.

We also tested other age-dependent decreasing forms of the threshold level as a negative linear function of age or different constant threshold levels in each age groups. None

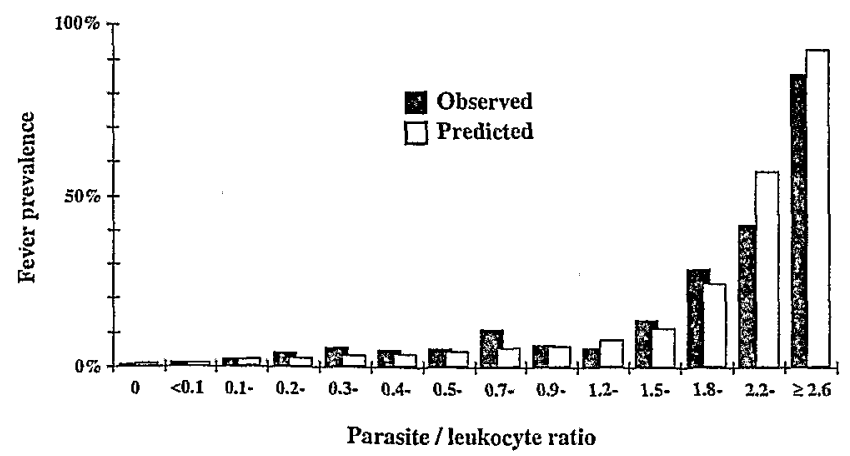

FIGURE 5. Prevalence of fever by parasite density in 5,735 observations from 200 permanent residents, including observations following antimalarial treatment in Dielmo, Senegal, June-September 1990. Stippled bars correspond to 204 observed fever cases. Blank bars correspond to predicted fever cases from the random-effect logistic regression model (model 5, Table 3 ). 


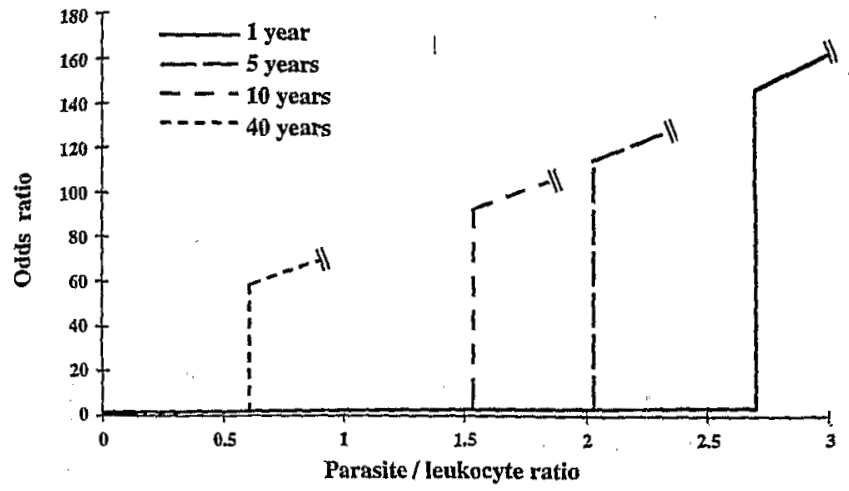

FIGURE 6. Estimated subject-specific odds ratio of fever by parasitemia and age.

of the corresponding models fitted better than the previousiy defined model.

Of 4,936 measurements of parasite density in asymptomatic subjects (control observations), only $14(0.3 \%)$ were higher than the age corresponding pyrogenic threshold. Parasitemia was above the threshold level in 61 (43.6\%) of the 140 fever cases observed.

Independent of the exclusion criteria that were taken into account in the analysis of the relationship between parasitemia and fever, parasite density was above the threshold level in 348 of the 8,636 observations made in the 247 inhabitants of Dielmo. Among these 348 observations, the temperature measured at the same time as the thick blood film was made was above $37.9^{\circ} \mathrm{C}$ in 151 cases (43.4\%). Among the 197 observations in which the temperature was less than or equal to $37.9^{\circ} \mathrm{C}, 128$ observations $(65 \%)$ were made during a pathologic episode during which a temperature greater than $37.9^{\circ} \mathrm{C}$ was observed. In 33 of the 197 apyretic observations $(16.7 \%)$, symptoms linked to fever were reported between $1 \mathrm{hr}$ and three days before or after the thick blood film was made. Finally, in 36 observations (18.3\%) no symptoms linked to the fever were reported. These 36 observations $(0.4 \%$ of the total apyretic observations) were made in 30 individuals of which 15 (20 observations) were part of one group of the population (50 of 247), which ceased to participate in the study after the month of Octopber 1990. During the systematic follow-up, parasitemias above the threshold were therefore associated with the occurrence of fever or fever-related symptoms in $89.7 \%$ (312 of 348) of cases. Fitting the model with the 8,636 observations made in the 247 inhabitants, we also came to the same conclusion of evidence for an age-dependent pyrogenic threshold.

\section{DISCUSSION}

Our analysis shows that the relationship between parasite density and fever risk is much better described as an agedependent discontinuous function than a continuous one. This suggests that there exists a pyrogenic threshold of parasite density and that the level of this threshold decreases with age.

There is now evidence that rupturing schizonts cause fever by releasing nonprotein toxins that stimulate macrophages to release tumor necrosis factor (TNF).22-25 The toxins charac- terized so far are nonprotein moieties able to induce neutralizing antibodies, and these $T$ cell-independent antigens need frequent boosting to maintain high and sustained antibody titers. ${ }^{26-31}$ In this view, the threshold level would be the parasite density corresponding to the maximum quantity of toxins able to be neutralized by these antibodies. As observed in nonimmune individuals in whom fever occurs even though parasitemia is still very low, the absence of neutralization of a small quantity of toxins could be responsible for an acute febrile episode. In children living in highly endemic areas, only a very high parasitemia can induce fever since the high prevalence of high parasite loads maintain high titers of antibodies against TNF-inducing toxins. In adolescents and adults, the progressive development of anti-parasite immunity results in a decrease in parasite density, and therefore a lower level of the short-lived antibodies to TNFinducing toxins. This scheme could explain the decrease of the threshold level with age.

By reason of the definition we used (presence of fever demonstrated by temperature measurement), our case observations have been made during clearly pathologic episodes. We obtained similar results in defining hyperthermia as temperatures greater than $37.6^{\circ} \mathrm{C}$ or $37.9^{\circ} \mathrm{C}$ and by using the minimum or maximum parasite density recorded during each febrile episode. This suggests that our conclusions are not dependent on the body temperature cutoff used to define hyperthermia. The case observations in which fever obviously or probably had a cause other than malaria were not excluded because it was impossible to rule out the hypothesis that malaria parasitemia played an associated role. That leads to an underestimating of the parasitemia-fever risk odds ratio. Since we excluded observations without hyperthermia but accompanied by fever-related symptoms, we can consider the control observations to be almost certainly apyretic. The occasional observation of very high parasitemia in asymptomatic individuals has often been an argument against using parasite density for the individual diagnosis of malaria attacks, $1,9,10$ We have found that these asymptomatic observations are very rare $(0.3 \%)$ and that parasitemia peaks are usually accompanied by fever or symptoms linked to fever during the preceding or following hours. Among the asymptomatic observations in which parasitemia was above the threshold, more than half were made in persons who possibly did not report all their symptoms. Our closely followed-up study made it possible, however, to detect even very brief febrile episodes that are linked with these high parasitemias and that are not always recorded during transversal studies or intermittent follow-up of cohorts.

Even if the present model needs to be prospectively validated in other areas and populations, it seems unlikely that the relationship between parasitemia and the occurrence of fever is fundamentally different among the inhabitants of Dielmo and other people living in highly endemic areas. In Tanzania,, 32 Papua New Guinea, ${ }^{33}$ and Dielmo, the power function was the best function used to describe the relation between parasitemia and risk of fever as a continuous function. The estimation of the exponent of this power function was equivalent in the three studies $(0.83,0.84$, and 0.82$)$. Interaction between the effect of age and that of parasitemia was also observed in Papua New Guinea. ${ }^{33}$ The threshold 
level that we identified is equivalent to that found in two populations in the Congo.4,6 This suggests that in different ethnic groups exposed to a comparable transmission level, the relationship between parasitemia and fever is similar.

The study lasted two months during a period when transmission was relatively low (June and August, nine and 13 infective bites/person/month, respectively) and two months of high transmission (July and September, 30 and 28 infective bites/person/month, respectively). The absence of interaction between the effects of month of survey and parasitemia suggests that the conclusions can be extrapolated to other transmission levels in the same location, as was also observed in Papua New Guinea. ${ }^{33}$

Furthermore, the absence of a significant subject-specific random effect suggests that the differences in threshold level between individuals of the same age can be sufficiently low in a given epidemiologic situation to allow the definition of an age-dependent threshold function applicable to the entire population. This observation was unexpected since one may have presumed that both differences in protective immunity, possible differences in the virulence of $P$. falciparum strains and random variations in parasite and leukocyte counts would affect the significance for fever risks of given parasite/leukocyte ratios. These effects tend to introduce a certain noise into the definition of a pyrogenic threshold, and theoretically would lead to a smooth increase in risk of fever with parasitemia. A series of smooth functions that allow a step change in fever risk were tested. None of these functions fitted better than the age-dependent threshold model, indicating that there is almost no overlap between parasitemias observed during malaria attacks and fully asymptomatic parasitemias. This enables a critical level of parasitemia for the individual diagnosis of malaria attacks in highly endemic areas to be defined.

Acknowledgments: We thank the villagers of Dielmo who made this study possible and all those ORSTOM, Institut Pasteur, Dakar University, and Service de Lutte Anti Parasitaire staff involved in the fieldwork and microscopy. We also thank P. Druilhe, M. Molyneux, T. Smith, C. Behr, O. Mercereau-Puijalon, and F. Dabis for helpful comments on the text and L. Pereira da Silva for encouragement and advice.

Financial support: This work received financial support from the Ministere de la Recherche et de l'Enseignement Superieur and the Ministere de la Cooperation et du Developpement (Paris).

Authors' addresses: Christophe Rogier, Institut Pasteur de Dakar, BP 220, Dakar, Senegal. Daniel Commenges, INSERM Unite 330, Universite de Bordeaux II, 146 rue Leo-Saignat, 33076 Bordeaux, France. Jean-Francois Trape, ORSTOM, BP 1386, Dakar, Senegal.

\section{REFERENCES}

1. Marsh K, 1992. Malaria, a neglected disease? Parasitology 104: S53-S59.

2. Greenwood BM, 1987. Asymptomatic malaria infections -Do they matter? Parasitol Today 3: 206-214.

3. Basset MT, Taylor P, Bvirakare J, Chiteka F, Govere E, 1991. Clinical diagnosis of malaria: can we improve?. $J$ Trop Med Hyg 94: 65-69.

4. Trape JF, Peelman P, Morault-Peelman B, 1985. Criteria for diagnosing clinical malaria among a semi-immune population exposed to intense and perennial transmission. Trans $R$ Soc Trop Med Hyg 79: 435-442.

5. Greenwood BM, Bradley AK, Greenwood AM, Byass P, Jammeh K, Marsh K, Tulloch S, Oldfield FSJ, Hayes R, 1987.
Mortality and morbidity from malaria among children in a rural area of The Gambia, West Africa. Trans $R$ Soc Trop Med Hyg 81: 478-486.

6. Richard A, Lallemant M, Trape JF, Carnevale P, Mouchet J, 1988. Le paludisme dans la region forestiere du Mayombe, Republique Populaire du Congo. III. Place du paludisme dans la morbidite generale. Ann Soc Belg Med Trop 68: 317-329.

7. Snow RW, Lindsay SW, Hayes RJ, Greenwood BM, 1988. Permethrin-treated bed nets (mosquito nets) prevent malaria in Gambian children. Trans R Soc Trop Med Hyg 82: 838-842.

8. Petersen E, Hogh B, Marbiah NT, Dolopaie E, Gottschau A, Hanson AP, Bjorkman A, 1991. Clinical and parasitological studies on malaria in Liberian adults living under intense malaria transmission. Ann Trop Med Parasitol 85: 577-584.

9. Smith T, Armstrong Schellenberg J, Hayes R, 1994. Attributable fraction estimates and case definitions for malaria in endemic areas. Stat Med 13: 2345-2358.

10. Rougemont A, Breslow N, Brenner E, Moret AL, Dumbo O, Dolo A, Soula G, Perrin L, 1991. Epidemiological basis for clinical diagnosis of childhood malaria in endemic zone in West Africa. Lancet 338: 1292-1295.

11. Velema JP, Alihonou EM, Chippaux JP, van Boxel Y, Gbedji E, Adegbini R, 1991. Malaria morbidity and mortality in children under three years of age on the coast of Benin, West Africa. Trans $R$ Soc Trop Med Hyg 85: 430-435.

12. Cox MJ, Kum DE, Tavul L, Narara A, Raiko A, Baisor M, Alpers MP, Medley GF, Day KP, 1994. Dynamics of malaria parasitaemia associated with febrile illness in children from a rural area of Madang, Papua New Guinea. Trans $R$ Soc Trop Med Hyg 88: 191-197.

13. Trape JF, Rogier C, Konate L, Diagne N, Bouganali H, Canque B, Legros F, Badji A, Ndiaye G, Ndiaye P, Brahimi K, Faye O, Druilhe P, Pereira da Silva L, 1994. The Dielmo project: a longitudinal study of natural malaria infection and the mechanisms of protective immunity in a community living in a holoendemic area of Senegal. Am J Trop Med Hyg 51: 123137.

14. Stiratelli R, Laird NM, Ware JH, 1984. Random-effects models for serial observations with binary response. Biometrics 40 : 961-971.

15. SERC, 1991. EGRET: User's Manual. Seattle: Statistics and Epidemiology Research Corporation.

16. Zeger SL, Liang KY, Albert PS, 1988. Models for longitudinal data: a generalized estimating equation approach. Biometrics 44: $1049-1060$.

17. Akaike H, 1974. A new look at the statistical model identification. IEEE Trans Automat Contr AC-19: 716-723.

18. Tsiatis AA, 1980. A note on a goodness-of-fit test for the logistic regression model. Biometrika 67: 250-251.

19. Christophers R, 1949. Endemic and epidemic prevalence. Boyd MF, ed. Malariology. Philadelphia and London: W. B. Saunders, 698-721.

20. Kitchen SF, 1949. Symptomatology: general considerations. Boyd MF, ed. Malariology. Philadelphia and London: W. B. Saunders, 966-994.

21. Bruce-Chwatt LJ, 1952. Malaria in African infants and children in southern Nigeria. Ann Trop Med Parasitol 46: 173-200.

22. Kwiatkowski D, Cannon JG, Manogue KR, Derami A, Dinarello CA, Greenwood BM, 1989. Tumor necrosis factor production in falciparum malaria and its association with schizont rupture. Clin Exp Immunol 77: 361-366.

23. Kwiatkowski D, Nowak M, 1991. Periodic and chaotic hostparasite interactions in human malaria. Proc Natl Acad Sci USA 88: 5111-5113.

24. Karunaweera ND, Grau GE, Gamage P, Carter R, Mendis K, 1992. Dynamics of fever and serum TNF levels are closely associated during clinical paroxysms in Plasmodium vivax malaria. Proc Natl Acad Sci USA 89: 3200-3203.

25. Kwiatkowski D, Molyneux ME, Stephens S, Curtis N, Klein N, Pointaire P, Smit M, Allan R, Brewster DR, Grau GE, Greenwood BM, 1993. Anti-TNF therapy inhibits fever in cerebral malaria. $Q J$ Med 86: 91-98.

26. Playfair JHL, Taverne J, Bate CAW, de Souza JB, 1990. The 
malaria vaccine: anti-parasite or anti-disease? Immunol Today 11: 25-27.

27. Bate CAW, Taverne J, Roman E, Moreno C, Playfair JHL, 1992. TNF induction by malaria exoantigens depends upon phospholipid. Immunology 75: 129-135.

28. Schofield L, Hackett 1993. Signal transduction in host cells by a glycosylphosphatidylinositol toxin of malaria parasites. $J$ Exp Med 177: 145-153.

29. Schofield L, Vivas L, Hackett F, Gerold P, Schwarz RT, Tachado $S$, 1993. Neutralizing monoclonal antibodies to glycosylphosphatidylinositol, the dominant TNF- $\alpha$-inducing toxin of Plasmodium falciparum: prospects for the immunotherapy of severe malaria. Ann Trop Med Parasitol 87: 617-626.

30. Bate CAW, Taverne J, Dave A, Playfair JHL, 1990. Malaria exoantigens induce $T$-independent antipody that blocks their ability to induce TNF. Immunology $70: 315-320$.
31. Bate CAW, Taverne J, Kwiatkowski D, Playfair JHL, 1993. Phospholipids coupled to a carrier induce IgG antibody that blocks tumour necrosis factor induction by toxic malaria antigens. Immunology 79: 138-145.

32. Alonso PL, Smith T, Armstrong Schellenberg JRM, Masanja $\mathrm{H}$ Mwankusye S, Urassa H, Bastos de Azevedo I, Chongela J, Kobero S, Menendez C, Hurt N, Thomas MC, Lyimo E, Weiss NA, Hayes R, Kitua AY, Lopez MC, Kilama WL, Teuscher T, Tanner M, 1994. Randomised trial of efficacy of SPf66 vaccine against Plasmodium falciparum malaria in children in southern Tanzania. Lancet 344: 1175-1181.

33. Smith T, Genton B, Baea K, Gibson N, Taime J, Narara A, AlYaman F, Beck HP, Hii J, Alpers M, 1994. Relationship between Plasmodium falciparum infection and morbidity in a highly endemic area. Parasitology 109: 539-549. 
The American Journal of

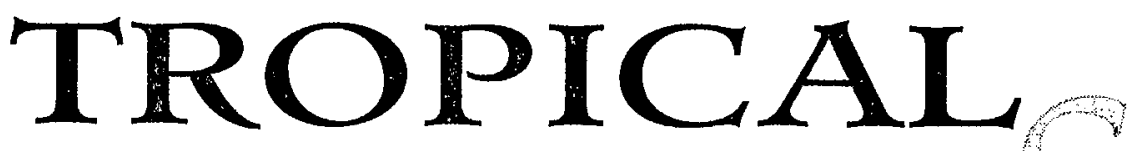

$155 N \quad 0002-9637$ Hoold D FRA
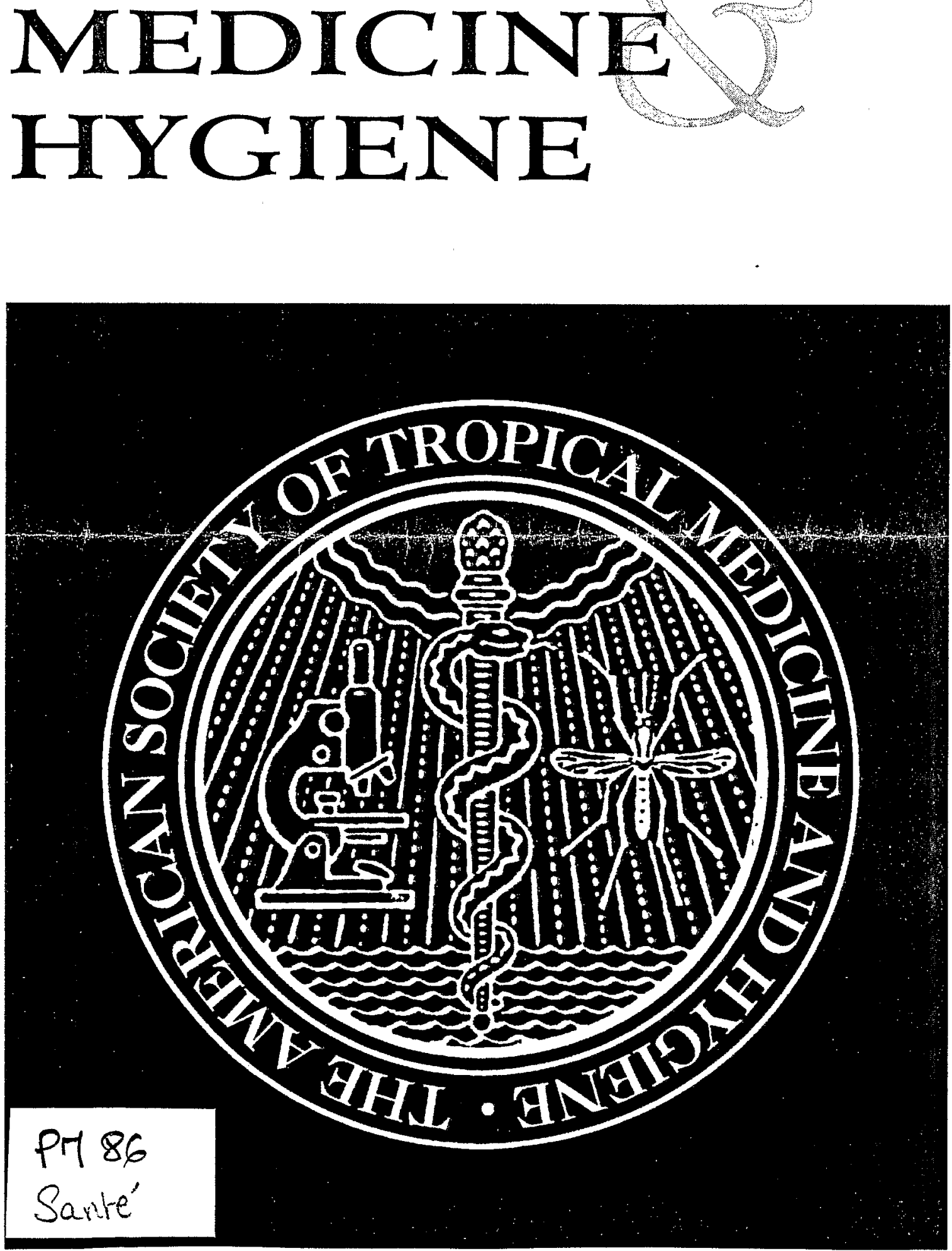

OFFICIAL ORGAN OF

THE AMERICAN SOCIETY OF TROPICAL MEDICINE AND HYGIENE 